\title{
COMMENTARY
}

\section{Reflexivity and food systems research}

\author{
David V. Fazzino* \\ Bloomsburg University of Pennsylvania
}

Submitted December 2, 2021 / Published online January 27, 2022

Citation: Fazzino, D. V. (2022). Reflexivity and food systems research.

Journal of Agriculture, Food Systems, and Community Development, 11(2), 19-22.

https://doi.org/10.5304/jafscd.2022.112.006

Copyright (C) 2022 by the Author. Published by the Lyson Center for Civic Agriculture and Food Systems. Open access under CC-BY license.

I went out there, in search of experience, to taste and touch, and to feel as much, as a man can, before he repents.

—“The Wanderer,” U2 featuring Johnny Cash, Zooropa, 1993

$\mathrm{T}$

his commentary is the result of an imperfect fit of much of the content below for a collection on sustainability and food. Ultimately I choose to remove this as it went through the review process, realizing it was a likely a round-(w)hole-square-peg type of situation. It was perhaps a bit tongue in cheek or "obtuse" for a more "scientific" way of considering the issue of food systems sustainability. In one of the disciplines from which I write, anthropology, the reflexive turn-refuting the outright positivism of neutral and objective studies, which make claims to a knowable and absolute truth-has become a part of the intellectual landscape for generations. This has led to more scientific studies wherein anthropologists are generally more honest about the extent and limitations of their research and writing. The ethnographic texts that implied omniscient and omnipresent accounts of the cultural group have generally faded from favor toward more partial accounts that are (1) reflexive in their thorough descriptions of the methods employed, and (2) those which disclose, to a greater or lesser extent, one's positioning. These lessons have not generally permeated larger-level discussions of global food systems. Below, I take up the idea of positioning, highlighting tensions that don't quite make the cut of being labeled or disclosed as a potential "conflict of interest" in academic publications, but nevertheless have

* David V. Fazzino, associate professor and chair in the Department of Anthropology at Bloomsburg University of Pennsylvania; 400 East Second Street, 150 CEH; Bloomsburg, PA, 17815 USA; +1-570-389-4859; dfazzino@bloomu.edu 
implications in terms of how research is conducted, written up, and ultimately becomes accepted knowledge in particular disciplinary and professional accounts.

As analysts of food systems, we should be clear about our own ideological and professional commitments that may be operating at cross-purposes to what, where, and how we write and report on global and local conditions of sustainability in food systems. Our lived experiences, in some instances, may create contradictions which, rather than being dismissable as one-offs, may offer signs of preferences and patterns with varying impact on how we conduct our research and writing on topics of sustainability. Through the process of writing and publishing, we create a particular context for our readers to imagine the world as it is and as it could be. This process is inherently one of discernment, wherein we choose the lens or lenses by which we define sustainability and the threat to sustainability for ourselves and our interlocutors.

Naturally, our self-reporting and sharing of aspects of our life is contingent upon our personal predilections, social and cultural factors, and those of our interlocutors. This is true not only in the context of writing but also fieldwork and engagement, including the use of interviewing that informs the work. Of course, we don't always toe the line (Figure 1).

\section{Figure 1. The author slugging down an ice-cold Coca- Cola to clear his palette after enjoying a pizza at the celebration of his parents' 50th wedding anniversary. Note the iWatch representing the "future of health" on his wrist.}

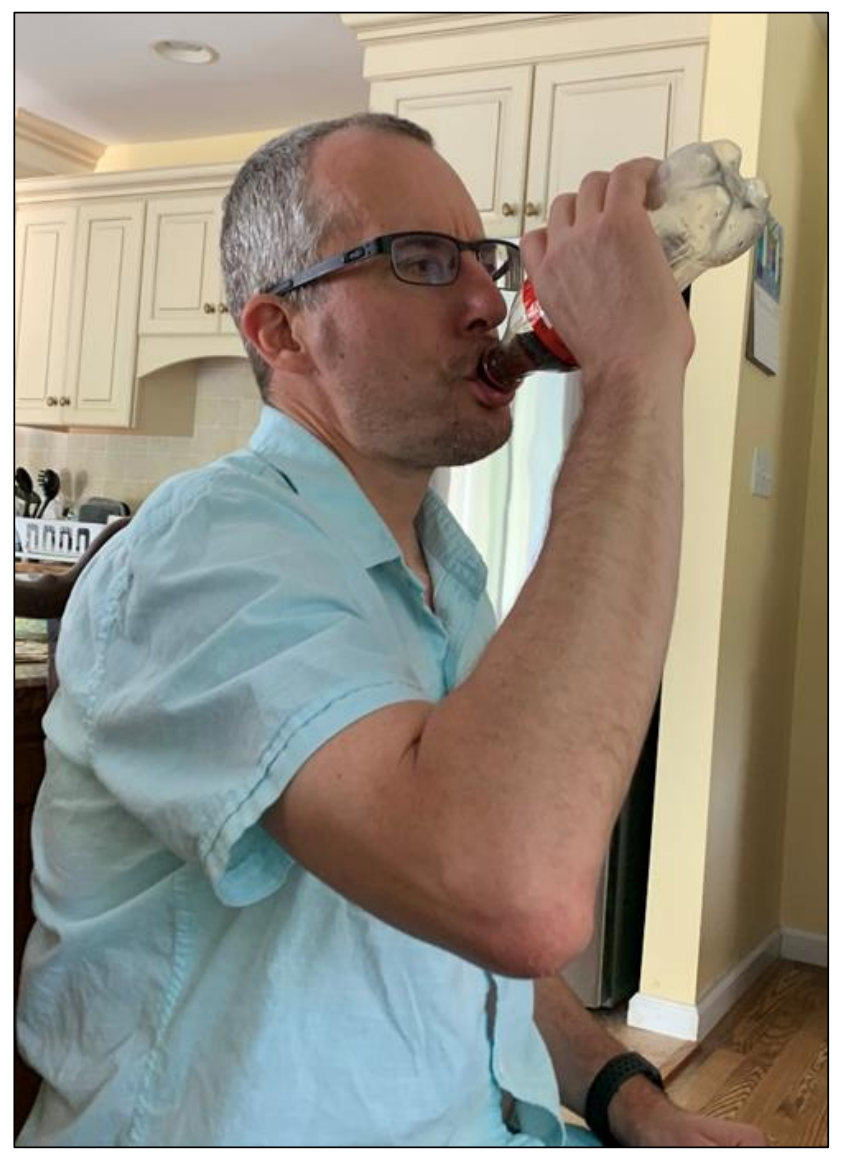

Photograph by Ashley Meredith.
Most accounts informing food systems give us a short biographical sketch of the author in order to convey a sense of general interests and current professional position. From this we might be able to contact authors or do our own research in order to consider how their professional training, professional roles and responsivities, and previous works inform their current work. We typically are left to additional internet searches to attempt to fill in the blank or gossip about personal behavior and decision-making"Did you see so-and-so eat fast food in the airport?" This is not to say that we should thoroughly engage in "navel-gazing" as the key component of our written work, but, rather, call on one another to pause and reflect on how our own considerations are informed by social, cultural, and inter(personal) affiliations which shape our work.

In terms of my own positioning, Figure 1 reveals a number of interrelated points about research on sustainable food systems. It alludes to several factors that inform how I can and am likely to write about food systems: (1) I am drinking Coca-Cola and eating pizza while writing about and researching sustainable food systems in diverse settings; (2) My diet is, in part, shaped by dietary choices and options my parents presented to me as a child; (3) They are eating the same thing, as we are sharing a meal in celebration with one another; there is a 
longevity issue here as we mark their 50-year wedding anniversary; (4) The iWatch is present on my wrist, a personal health and fitness monitoring device that indicates potential substantial investment in personal health; (5) I am white, indicating privilege, particularly when coupled with the next point; (6) The surroundings indicate relative class-based affluence in the U.S., indicating that I am likely not currently experiencing food insecurity and probably never have. This disclosure, albeit partial, serves to illustrate the point of intellectual and ideological cross-cutting commitments.

These have real world impacts in terms of how I have conducted research on food systems. For example, I reported the shifting nature of knowledge and perceptions of traditional foods along generational lines in Tohono O'odham Nation (TON) in southern Arizona, using the broad categories of young adult, middle-age adult, and elder (Fazzino, 2008). The importance of locally produced food has entered these discussions of identity and food sovereignty, as they are healthier options that will help turn the tide of the nutritional and social consequences of increased consumption of imported goods (Fazzino, 2008). My research on the TON highlighted many issues with continuity and change in the context of the traditional food system, as young adults (those aged 18-39) were more likely than elders (those aged 60 and above) to name introduced foods as traditional (Fazzino 2008). What I neglected to include in reporting of these accounts was the reported change over time, measured in and through the reflections on dietary change in the context of one person's life. I attempt to remedy this omission below, and in doing so, hope to set the stage for a broader discussion of sustainability perspectives and illustrate the value of incorporating reflexivity into our work in promoting sustainable food systems.

One elder shared the historical shifts that occurred over his lifetime, maintaining that "It seems like that's what made people healthy back then, the foods that they ate off the land." These foods were not always readily available due to structural shifts, such as a proliferation of wage employment, boarding schools, and World War II enlistment. These made it less likely for Tohono O'odham to grow or eat locally, creating a situation wherein the TON food system relies on imported foods. He eloquently shared, "[In the cotton camps] there's only store-bought food. ... But even going away to boarding school there was a change in your diet because ... you're eating food that's made in the cafeteria. ... Even when we got rations here, [the] food commodities, that made a change in our diet. ... [Also] I think when the people started going off to war, to the cotton fields, jobs came about here in Sells or other places. ... And when you were doing your job you didn't have too much time to work in your field ... and then finally it just stopped."

He shared that he sometimes lost sight of the importance of traditional ways in his youth. Some of this was due to the structural shifts away from locally produced foods on the TON and subsequent increases in noncommunicable diseases led to a series of initiatives from TON agencies and nonprofit organizations to grow, collect, and promote the consumption of traditional foods (Fazzino, 2008). The Native American Advancement Foundation (2021) has been active in this process through the creation of Ruth's Garden in the TON's GuVo District.

Hence, while I was reporting on the lack of knowledge or even desire to consume locally grown preContact traditional foods in relation to age (Fazzino, 2008), I underestimated the importance of time in transforming individual perspectives. The semi-structured interviews performed were able to explore the nuances of an individual's preferences and knowledge at that discrete moment in time. This data source was inadequate to speculate on a continual shift toward more globalized and less sustainable foods by the population as a whole, as I suggested (Fazzino, 2008). The focus on a generational shift toward less sustainable diets was overestimated in light of the stories of redemption toward greater consumption of locally produced foods that elders shared with me. This example highlights a potential pitfall in reporting and reflecting on sustainable diets, namely a lack of transparency surrounding the ideological commitments of the researchers and authors. In this instance it was a narrative of decline and loss of traditional 
foodways to industrial and imported foods that permeated the analysis and writing. In my deployment of this lens of decline, I lost out on the power of redemption, choice, and agency that was being made, and continues to be made, in the TON and in a variety of other contexts today.

\section{References}

Fazzino, D. (2008). Continuity and change in Tohono O'odham food systems: Implications for dietary interventions. Culture \& Agriculture, 30(1-2), 38-46. https://doi.org/10.1111/j.1556-486X.2008.00006.x

Native American Advancement Foundation. (2021). Food sustainability. https://www.naafnow.org/food 